\title{
AVALIAÇÃO DA ACESSIBILIDADE DAS FUNÇÕES DE PRIVACIDADE DO FACEBOOK COM PESSOAS COM DEFICIÊNCIA VISUAL.
}

\author{
Adriano Pessini (UDESC, Brasil) adriano.pessini@gmail.com \\ Jucilane Rosa Citadin (UDESC, Brasil) jucilane.rosa@gmail.com \\ Avanilde Kemczinski (UDESC, Brasil) avanilde@joinville.udesc.br \\ Isabela Gasparini (UDESC, Brasil) isabela@joinville.udesc.br
}

Resumo: A forte presença das redes sociais on-line nas interações e relações humanas tem estimulado a reflexão de diversos pesquisadores, inclusive na comunidade de Interação Humano-Computador (IHC). Uma das maiores preocupações das redes sociais está na questão da privacidade e, em relação à inclusão social e digital, na questão da acessibilidade. Assim, este artigo relata a avaliação da acessibilidade das funções de privacidade do Facebook com usuários cegos que usam o aplicativo por meio de leitores de tela. A pesquisa foi realizada utilizando-se uma abordagem qualitativa, através de entrevistas, observação direta das atividades propostas aos participantes e anotações, apontando uma série de dificuldades no uso dos recursos de privacidade do Facebook por este público-alvo.

Palavras Chave: Avaliação de acessibilidade, pesquisa qualitativa, funções de privacidade, Facebook.

\begin{abstract}
The strong presence of social networks in online interactions and human relations has stimulated reflection of several researchers, including the community of Human-Computer Interaction (HCI). A major concern of social networks is the issue of privacy and, in relation to social and digital inclusion, the issue of accessibility. Thus, this paper reports the accessibility of Facebook's privacy functions with blind users who use the application by screen readers. The survey was conducted using a qualitative approach, through interviews, direct observation of the activities proposed to the participants and notes, pointing to a series of difficulties in the use of Facebook's privacy for this target audience.
\end{abstract}

Keywords: Accessibility evaluation, qualitative research, privacy functions, Facebook. 


\section{Introdução}

Atualmente as redes sociais fazem parte do cotidiano, acessadas continuamente por meio de diferentes plataformas e dispositivos, por um número cada vez maior de pessoas [4]. A difusão de tecnologias computacionais nas relações humanas e seus impactos tem sido alvo de estudos de pesquisadores das mais diversas áreas. Cabe aos profissionais da área de IHC (Interação Humano-Computador) refletir sobre como pode contribuir para a qualidade das interações humanas mediadas por tecnologias computacionais e avaliar as interfaces que permitem essas interações. Uma das maiores preocupações nas interações humanas nas redes sociais é a privacidade. Desta forma este trabalho propõe a avaliação das funções de privacidade do Facebook, rede social de maior destaque atualmente [4].

O Facebook é uma rede social cuja missão é "criar um mundo mais aberto e transparente" [10]. Entretanto, a perspectiva de um mundo mais aberto contempla um mundo mais acessível? Esta questão nos impele a investigar os aspectos de acessibilidade das funções de privacidade do Facebook.

Segundo a Associação Latino-Americana de Integração (ALADI) [1], a acessibilidade está conectada a aspectos socioeconômicos e tecnológicos que permitam que essas redes se estabeleçam efetivamente e que o maior número de pessoas esteja integrado ativamente. A ALADI [1] afirma ainda que a ausência de acesso à informação no contexto da rede deve ser considerada na análise da acessibilidade para que seja possível mensurar a distância tecnológica entre indivíduos, famílias, empresas, grupos de interesses, países e áreas geográficas em suas oportunidades de acesso à informação e às tecnologias da comunicação e o uso da Internet para um amplo desenvolvimento de atividades.

A Organização Mundial da Saúde (OMS) classifica a deficiência visual em diversos níveis: leve, moderada, profunda, severa e perda total da visão [11].

Segundo Pascolini e Mariotti [9], existem no mundo aproximadamente 285 milhões de pessoas com deficiência visual das quais 39 milhões são cegas. No Brasil, de acordo com o Censo Brasileiro de 2010 (IBGE), 6,7\% da população total, que é de aproximadamente 191 milhões de brasileiros, tem alguma deficiência severa. A deficiência visual severa foi a que mais incidiu sobre a população com $3,5 \%$ das pessoas declarando possuir grande dificuldade ou nenhuma capacidade de enxergar [7]. Esse percentual representa mais de 6 milhões de brasileiros com deficiência visual severa.

Entre tantas possibilidades que poderiam ser avaliadas, diante destes números, optou-se por focar a avaliação da acessibilidade das funções de privacidade do Facebook para os deficientes visuais com perda total de visão. Assim, este trabalho segue relatando as etapas e resultados da avaliação realizada, além do referencial teórico que embasa a avaliação. 


\section{Fundamentos}

\subsection{Deficiência Visual}

A Organização Mundial da Saúde (OMS) define deficiência como qualquer perda ou anormalidade da estrutura ou função psicológica, fisiológica ou anatômica. Representa a exteriorização de um estado patológico e, em princípio, reflete distúrbios no nível do órgão [11]. A deficiência visual caracteriza-se pela perda total ou parcial, congênita ou adquirida, da visão [6].

\subsection{Acessibilidade}

Historicamente pessoas com alguma deficiência sofrem com a exclusão nos meios de comunicação e informação. A sociedade vem trabalhando a acessibilidade, mas tem dificuldades na inclusão plena dos deficientes nos ambientes e atividades cotidianas.

De acordo com a iniciativa da World Wide Web Consortium (W3C), chamada Web Accessibility Initiative (WAI), a acessibilidade na Web significa que as pessoas com deficiência possam utilizar a web, que possam perceber, compreender, navegar, interagir e contribuir com a web [12].

De acordo com Dias [5] a acessibilidade é o quanto um produto possa ser flexível o suficiente para atender às necessidades e preferências de um vasto número de pessoas, e ser ainda compatível com tecnologias assistivas.

A acessibilidade na web refere-se a prática de conceber sites que possam ser utilizados por qualquer pessoa, independente de plataforma, dispositivo ou limitações físicas e cognitivas. Quando os sites são corretamente projetados, desenvolvidos e implementados, todos os usuários podem ter igual acesso à informação.

\subsection{Tecnologias Assistivas}

A área que engloba as tecnologias assistivas é uma área interdisciplinar, que estuda produtos, recursos, metodologias, estratégias, práticas e serviços que objetivam promover a funcionalidade, relacionada à atividade $\mathrm{e}$ participação, de pessoas com deficiência, incapacidades ou mobilidade reduzida, visando sua autonomia, independência, qualidade de vida e inclusão social [2].

As pessoas com deficiência visual total, geralmente utilizam softwares leitores de tela, que são as tecnologias assistivas utilizadas para acessar páginas na internet e aplicativos. Esses softwares leitores de tela permitem a navegação nas páginas traduzindo o texto eletrônico em texto falado por meio dos sintetizadores de voz [5].

O Jaws foi lançado em 1989 nos Estados Unidos, constitui uma das principais aplicações leitoras de tela usada em escala mundial. Atualmente é comercializado pela Freedom Scientific, e está na sua versão 13 (inglês) e 12.0 (português). Algumas características são: disponibiliza versão para testes, trabalha praticamente com todas as versões do Windows para microcomputadores, lê telas em diversos idiomas, apresenta facilidade na instalação e apoio por voz durante todo o processo, faz a indicação das janelas ativas, do 
tipo de controle e suas características, entre outras [3].

Destaca-se também o aplicativo NonVisual Desktop Access [8] (NVDA, em português: Acesso Não-Visual ao Ambiente de Trabalho) que é um leitor de tela livre e gratuito para o sistema operacional Windows iniciado em 2006. Atualmente, o projeto é patrocinado por organizações como Mozilla Corporation e Adobe Systems Inc e por um grupo de desenvolvedores independente, e está na versão 2012.2.1.

\section{Etapas da avaliação}

Nesta seção são apresentados detalhes referentes ao processo de avaliação realizado.

\subsection{Objetivo e Escopo}

Conforme já mencionado o objetivo desta avaliação é avaliar a acessibilidade das funções de privacidade do Facebook com deficientes visuais com perda total de visão. Além do público-alvo da avaliação a equipe definiu a plataforma desktop como plataforma da avaliação. O sistema operacional utilizado foi o Windows (nas versões 7 e XP) e os navegadores Internet Explorer 8.0 e Firefox 11.0. Como os deficientes visuais necessitam de tecnologia assistiva para o acesso ao Facebook, foi utilizado o Jaws nas versões 12.0 e 13.0 e também o NVDA na versão 2011.2, conforme disponibilizado pelas associações nas quais foram realizadas as atividades ou pelos próprios participantes em seus computadores pessoais.

\subsection{Definição do público-alvo}

Como requisitos para participação, o públicoalvo foram os deficientes visuais com perda total de visão, com acesso a internet e com conta cadastrada no Facebook para possibilitar a pesquisa.

Para identificar possíveis participantes com o perfil desejado foram contatadas as instituições Associação dos Cegos do Vale do Itajaí (ACEVALI), sediada em Blumenau-SC, e a Associação Joinvilense para Integração dos Deficientes Visuais (AJIDEVI), sediada em Joinville-SC. Estas organizações se colocaram a disposição para colaborar com a pesquisa auxiliando na identificação de pessoas com deficiência visual que utilizassem o Facebook, colocando sua infra-estrutura a disposição e fornecendo informações adicionais sobre a utilização do Facebook por deficientes visuais. Visita a ACEVALI

A ACEVALI foi fundada em 28 de fevereiro de 1987 quando suas ações eram voltadas à alfabetização de deficientes visuais através do sistema Braille e pelo repasse de noções de orientações e mobilidade. Naquela época a associação ocupava um espaço cedido pela Prefeitura de ACEVALI e contava com dois funcionários e um número pequeno de associados.

Atualmente, a ACEVALI tem sede própria, conta com cerca de 180 associados de diversas faixas etárias e oferece serviços no sentido de garantir a inclusão social dos deficientes visuais e acesso aos serviços públicos 
garantidos por lei, como saúde, educação, esporte, cultura, entre outros. A associação conta com funcionários dedicados $\mathrm{e}$ voluntários. Os recursos financeiros são obtidos por meio de parcerias com empresas privadas, Fundo Municipal de Assistência Social além de doações de pessoas físicas.

A equipe entrou em contato com a Assistente Social e a Professora de Informática da ACEVALI para buscar o apoio da associação na localização de deficientes visuais que usassem o Facebook. A associação prontamente se colocou a disposição para colaborar, porém informou que haveria um número reduzido de deficientes que se encaixavam nos requisitos estipulados pela equipe. $\mathrm{O}$ número reduzido de deficientes visuais que utilizam o Facebook ocorre devido as redes sociais não serem ensinadas no curso de informática básica da ACEVALI, isto é, os deficientes visuais não tem contato com as redes sociais no curso. Além disso, a associação ficou sem professor de informática por alguns meses e o sistema usado pela mesma é o DosVox, que não possibilita o acesso as redes sociais na versão utilizada.

Apesar destas dificuldades, a equipe foi colocada em contato com um jovem deficiente visual que tinha perda total da visão e se enquadrava nos requisitos estipulados pela equipe.

Visita a AJIDEVI

A AJIDEVI foi fundada em 06/03/1981. É uma ONG (Organização Não Governamental) com a missão de possibilitar a promoção e integração social do deficiente visual (cego e baixa visão) em todas as faixas etárias, através de sua habilitação e reabilitação. Conta com aproximadamente 760 associados e atende diretamente aproximadamente 150 pessoas com deficiência visual total ou baixa visão, desde bebês até a terceira idade. A associação oferece curso de informática aos deficientes visuais interessados, no entanto o curso é de nível básico e observou-se que a maioria dos alunos estava iniciando a interação com o computador e não possuía conta no Facebook. Entretanto, a associação forneceu à equipe o contato de pessoas que já passaram pelo curso e que já estão integradas socialmente, algumas inclusive trabalhando. Algumas destas pessoas que já passaram pela associação tornam-se voluntárias em alguma atividade da mesma, para contribuir com o grupo. É o caso do participante que foi escolhido para o piloto da avaliação. Este participante interessa-se bastante por computador e tecnologias e ajuda voluntariamente no curso de informática em conjunto com a professora. A instituição empenhou-se em passar as informações necessárias e familiarizar a equipe com os recursos e ferramentas utilizados pelos deficientes visuais.

Como o foco de IHC é a qualidade das interações humanas mediadas por tecnologias computacionais, em conversa com a coordenadora pedagógica foi colocada a seguinte questão: "As interações com o computador e as mídias/redes sociais contribuem para a melhoria nas relações humanas do grupo?". Segundo a coordenadora "O computador e as tecnologias, assim como o 
Braile foi há anos atrás, foi um marco na melhoria da qualidade das relações dos deficientes visuais". Através do computador muitos se relacionam com pessoas de vários lugares, fazendo muitas amizades, inclusive muitos se conhecem através das redes sociais e interações virtuais das quais participam, e já houve até casamentos nesse meio.

Das pessoas identificadas e contatadas, confirmaram-se cinco participantes disponíveis para a pesquisa.

\subsection{Metodologia utilizada}

Visto a dificuldade em encontrar participantes específicos para a avaliação de acessibilidade e pela natureza do tipo de avaliação, a equipe trabalhou com uma abordagem qualitativa. A pesquisa foi realizada com a participação de 6 usuários, um participante do teste piloto e outros 5 para a pesquisa de fato, utilizando-se as técnicas de observação direta, anotação em papel e entrevistas semiestruturadas. Todos os participantes assinaram termo de consentimento livre e esclarecido, no qual foram informados de forma clara e objetiva sobre os procedimentos da pesquisa, do sigilo de seus dados, da voluntariedade e possibilidades de se retirar da pesquisa caso desejassem. Foram realizadas entrevistas coletando dados e a opinião dos entrevistados sobre a interação, além da observação direta das atividades propostas e a anotação de dados relativos ao processo. Todos estes dados foram analisados posteriormente.

Por se tratar de abordagem qualitativa e também pelo público em questão, a participação ativa dos usuários é fundamental. Entrevista e observação direta apresentam-se como boas técnicas a serem utilizadas pois, o entrevistador pode guiar o entrevistado e observar a atividade em tempo real, e pode captar informações que não seriam possíveis com outras técnicas.

O trabalho com os participantes foi dividido em três etapas. Primeiramente foi apresentado o questionário para a coleta de dados de perfil do usuário. Foram elaboradas 11 questões para conhecer aspectos como tempo e experiência do usuário com o uso de computador, internet, Facebook e seus recursos de privacidade.

$\mathrm{Na}$ segunda etapa, foi solicitado aos usuários que realizassem três atividades, com diferentes níveis de dificuldade, relacionadas com a privacidade no Facebook. Nesta etapa o entrevistador preencheu uma ficha, na qual informações sobre a execução das atividades foram registradas, como problemas técnicos, indicador de conclusão das tarefas, tempo decorrido, entre outros. A terceira e última etapa consiste no fechamento da entrevista onde o entrevistado pôde deixar os comentários que desejasse.

Todo o processo foi individual com cada participante e para a realização de cada entrevista foi adotado o seguinte procedimento: leitura e assinatura do termo de consentimento, realização de perguntas introdutórias de perfil (etapa 1 questionário), realização das atividades pelo entrevistado (etapa 2) e, paralelamente, registro de observações pelo entrevistador (ficha do avaliador) e, por fim, a etapa 3, a entrevista 
semiestruturada, registrando a percepção do entrevistado sobre a interação com o Facebook e sobre a pesquisa.

\subsection{Atividades no Facebook}

Conforme mencionado anteriormente, para avaliar a acessibilidade dos recursos de privacidade do Facebook se propôs aos entrevistados a realização de algumas atividades as quais são descritas a seguir:

- A1: Configure a privacidade padrão da sua conta para que apenas seus amigos possam ver.

- A2: Envie uma mensagem indicando que apenas os seus amigos possam vê-la.

- A3: Configure a prévia pública para que apareça (ou não) o seu Perfil em mecanismos de busca.

\subsection{Realização do Teste Piloto}

O teste piloto foi realizado com um participante considerado experiente no uso do computador, e de modo geral, considerado um usuário avançado (ele é voluntário na associação $\quad$ AJIDEVI), escolhido propositadamente, para que o questionário e as atividades propostas fossem avaliados $\mathrm{e}$ comentados por este participante ajustando o que fosse necessário conforme observação feita pela equipe. A avaliação foi feita na versão para desktop, no site facebook.com.br, utilizando sistema operacional Windows 7, navegador Internet Explorer versão 8.0 e Jaws versão 12.0. Na primeira etapa da avaliação tudo transcorreu bem, sendo que as 11 perguntas efetuadas foram respondidas sem problemas. Foi mantida então a etapa 1 conforme definida inicialmente.

$\mathrm{Na}$ segunda etapa, inicialmente foram propostas cinco atividades:

- A1: Configure a privacidade padrão da sua conta para que apenas seus amigos possam ver.

- A2: Envie uma mensagem indicando que apenas os seus amigos possam vê-la.

- A3: Configure quem pode lhe enviar solicitação de amizade e mensagens.

- A4: Configure quem pode publicar no seu mural/linha do tempo e quem pode ver as suas publicações.

- A5: Configure a prévia pública para que apareça (ou não) o seu Perfil em mecanismos de busca.

$\mathrm{Na}$ observação feita pela equipe, percebeu-se que esta etapa foi muito cansativa, pois despendeu mais tempo do que o previsto, mesmo sendo o participante um usuário considerado avançado.

Desta forma, as tarefas a serem realizadas foram ajustadas para três atividades e o tempo para a realização ficou livre, pois a equipe contou com participantes distintos quanto a experiência no uso de computadores, e uma restrição de tempo poderia prejudicar alguns usuários. Foram escolhidas três atividades (A1, A2 e A5) dentre as cinco propostas inicialmente, mantendo-se uma em cada nível de dificuldade (fácil, médio e difícil), conforme observação feita pela equipe na 
realização do piloto.

Das cinco atividades propostas no teste piloto, a atividade A1 foi realizada na sua totalidade em aproximadamente 10 minutos e com um total de aproximadamente 15 passos, sendo que não foram registrados problemas técnicos na execução desta atividade. O participante demonstrou não saber ao certo onde configurar, o que exigiu certo direcionamento do entrevistador, e demorou um pouco para se localizar devido ao fato de ter que percorrer com a tecla $\mathrm{TAB}$ os links até que o link desejado fosse encontrado.

A atividade A2 não foi concluída em razão de o Facebook não abrir o botão de privacidade necessário (figura 1) através do teclado quando utilizado o leitor de tela (só funcionou com o mouse, o que impossibilita pessoas com deficiência visual total de realizarem essa tarefa no sistema). O botão de privacidade deveria abrir o submenu (figura 2) para a escolha de quem pode ver a mensagem publicada (status).

\section{FIGURA1 - BOTÃO DE PRIVACIDADE, ANTES DO BOTÃO PUBLICAR}

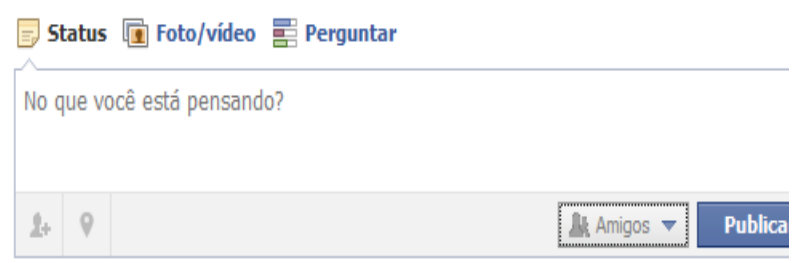

Fonte: Os autores (2012)

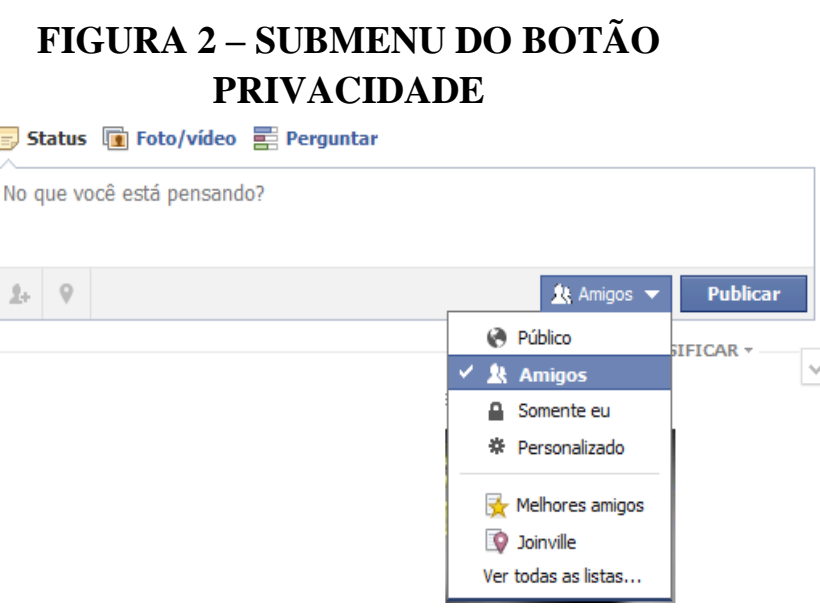

Fonte: Os autores (2012)

A atividade A3 não foi concluída, pois o sistema travou, devido o botão estar em inglês (figura 3), o que não foi compreendido pelo usuário no momento que o leitor de tela passou pelo botão. $\mathrm{O}$ usuário seguiu sem confirmar o botão e o sistema voltou ao início da página.

As atividades A4 e A5 foram realizadas em aproximadamente 5 minutos cada uma, com um total de aproximadamente 10 passos cada, sendo que não foram registrados problemas na execução das mesmas, ainda que foi preciso certo direcionamento para concluí-las, conforme feito na atividade A1.

\section{FIGURA 3 - BOTÃO EM INGLÊS - (DONE). LIDO PELO LEITOR DE TELA COMO "DONE BOTÃO".}

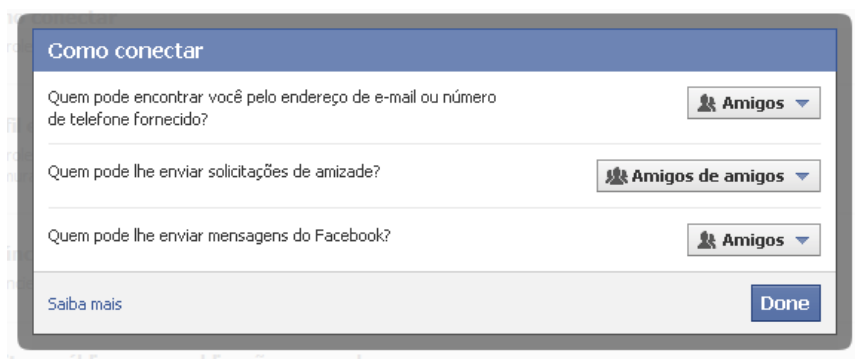

Fonte: Os autores (2012)

$\mathrm{Na}$ versão final das atividades foi mantida a atividade A2 que apresentou problemas através 
do leitor de tela (só funcionou com o mouse), para validar se ocorreriam os mesmos problemas com os demais. A atividade $\mathrm{A} 3$ foi suprimida para a realização da pesquisa, devido ao problema apresentado e também a atividade A4, devido ao tempo total excessivo observado pela equipe para a finalização de todas as atividades.

Assim, as atividades A1, A2 e A5, passaram a ser A1, A2 e A3 respectivamente.

$\mathrm{Na}$ etapa final, onde o entrevistado poderia deixar quaisquer comentários que desejasse sobre a pesquisa e sobre a interação com o Facebook, foi anotada a ocorrência do problema na atividade A2 que só funcionou com o mouse, sugerindo o usuário que poderia ser melhorada a interação com o Facebook para corrigir estes problemas.

Nas visitas iniciais a associação e na aplicação do piloto, observou-se que a interação com o Facebook é dificultosa, mesmo para um usuário mais experiente. Todas as atividades exigiram vários passos para serem executadas. Em conversa com o usuário piloto sobre essas dificuldades na interação, o mesmo mencionou não utilizar mais o Facebook devido a estes problemas e preferir usar o Twitter ao Facebook.

\section{Resultado da pesquisa}

Nesta seção são demonstrados os resultados da pesquisa com os 5 participantes.

Todos os cinco entrevistados usam o computador a mais de um ano. Porém, três deles relataram usar o Facebook a menos de seis meses. A frequência de uso do Facebook identificada é diariamente (três respostas) e de duas a três vezes por semana (duas respostas). Assim, os entrevistados podem ser qualificados como usuários ativos do Facebook. O grau de importância da privacidade relatado pelos entrevistados ficou como Muito Importante (três respostas) e Importante (duas respostas). Entretanto, apenas dois entrevistados relataram usar os recursos de privacidade disponíveis. Esta disparidade entre o grau de importância da privacidade e o uso dos recursos de privacidade do Facebook consiste no fato de que os entrevistados que não usam estes recursos relatarem que não publicam conteúdos pessoais ou que possam comprometer sua imagem.

A seguir serão relatadas as cinco entrevistas realizadas, individualmente.

\subsection{Entrevista 1}

O entrevistado número 1 possui um perfil mais iniciante na utilização do computador, apesar de utilizá-lo a mais de 1 ano, dentre os entrevistados é o que utiliza menos tempo o computador. A avaliação foi feita na versão para desktop, no site facebook.com.br, utilizando sistema operacional Windows 7 , navegador Internet Explorer versão 8.0 e Jaws versão 12.0. Na primeira etapa da avaliação tudo transcorreu bem, sendo que as 11 perguntas efetuadas foram respondidas sem problemas. Na segunda etapa, a atividade A1 foi realizada na sua totalidade em aproximadamente 15 minutos e com um total de aproximadamente 15 passos, sendo que não 
foram registrados problemas técnicos na execução desta atividade. $\mathrm{O}$ entrevistado demonstrou não saber onde configurar, o que exigiu total direcionamento do entrevistador, e houve demora para a localização da tarefa devido ao fato do participante ter que percorrer com a tecla TAB os links até que o link desejado fosse encontrado.

A atividade A2 não foi concluída devido o Facebook não abrir o botão necessário através do teclado quando utilizado o leitor de tela, mesmo caso do teste piloto, porém nesta interação o sistema aparentemente travou (para o observador), mas o leitor de tela voltou ao início da página e começou a leitura da página novamente. Foi feita mais uma tentativa para a realização da tarefa e observou-se que realmente não foi possível efetivá-la, pois o botão necessário não é aberto e volta ao início da página.

A atividade A3 foi realizada na sua totalidade em aproximadamente 20 minutos e com um total de aproximadamente 25 passos, sendo que não foram registrados problemas técnicos na execução desta atividade. O entrevistado demonstrou não saber onde configurar, o que exigiu total direcionamento do entrevistador, e demorou um pouco para localizar devido ao fato de ter que percorrer com a tecla TAB os links até que o link desejado fosse encontrado. $\mathrm{Na}$ etapa final, onde o entrevistado poderia deixar quaisquer comentários que desejasse sobre a pesquisa e sobre a interação com o Facebook, foi comentado sobre a dificuldade da interação, mencionando que poderia melhorar. No entanto, comentou ser melhor acessar com o Jaws do que com o NVDA (outro leitor de tela, que é gratuito).

Nesta entrevista ficou clara a dificuldade de navegação, especialmente para um usuário de perfil mais iniciante. As atividades exigiram muitos passos para serem executadas além do direcionamento pelo entrevistador no decorrer da execução das mesmas.

\subsection{Entrevista 2}

O entrevistado número 2 é um jovem com menos de 20 anos de idade e que possui mais de 6 anos de experiência no uso do computador. Devido a escassez de docentes aptos a lecionar informática para deficientes visuais este entrevistado é periodicamente convidado a atuar como professor na ACEVALI devido a sua experiência no uso do computador. Este entrevistado tem perda total da visão desde seu nascimento.

Devido a compromissos do entrevistado, o processo de entrevista teve que ser dividido em dois dias: no primeiro, foi aplicada a etapa 1 do questionário e realizada a primeira atividade A1, da etapa 2. No segundo dia foram executadas as demais atividades da etapa 2 e a etapa 3, sendo que em ambos os dias o entrevistador registrou suas observações sobre o processo.

No primeiro dia o entrevistado estava usando sistema operacional Windows XP, navegador Internet Explorer versão 8.0 e Jaws versão 12.0. Devido as dificuldades percebidas no teste piloto e na Entrevista 1, decidiu-se fazer o acesso ao site do Facebook por meio do link m.facebook.com o qual é destinado a 
dispositivos móveis de comunicação. No momento em que acessou o site e informou seu nome de usuário e senha o navegador solicitou que a senha fosse armazenada. Esta mudança no comportamento do navegador dificultava o prosseguimento da entrevista haja vista que não havia como o entrevistado selecionar uma opção somente com o teclado. Esta situação forçou o observador a intervir e selecionar a opção de não memorizar a senha para que o entrevistado pudesse acessar a página principal do Facebook.

$\mathrm{Na}$ primeira etapa da avaliação tudo transcorreu bem, sendo que as 11 perguntas efetuadas foram respondidas sem problemas. Na segunda etapa, a atividade A1 foi realizada na sua totalidade em aproximadamente 3 minutos e com um total de 15 passos, sendo que não foram registrados problemas técnicos na execução desta atividade. O entrevistado demonstrou que conhecia a existência da configuração solicitada, mas demorou a localizá-la devido ao fato de ter que percorrer com a tecla $\mathrm{TAB}$ os links até que o link desejado fosse encontrado.

$\mathrm{Na}$ atividade A2 o entrevistado localizou rapidamente o link de acesso ao formulário de envio de mensagens por meio da janela "Elementos do Jaws", um recurso do aplicativo de leitura de telas que apresenta todos os links presentes na página sendo exibida. Entretanto, a atividade teve que ser interrompida, pois não foi possível selecionar os destinatários da mensagem usando o navegador Internet Explorer, mesmo caso do piloto. Diante do impasse, o entrevistado relatou que era possível realizar a atividade usando o navegador Firefox e, devido ao curto espaço de tempo restante, a entrevista foi encerrada para que o ambiente pudesse ser modificado e o navegador Firefox instalado.

No segundo dia de entrevista, utilizando o navegador Firefox 11.0 e o aplicativo de leitura de tela NVDA versão 2011.2 em um computador com Windows XP e acessando o Facebook por meio do link m.facebook.com, a atividade A2 foi retomada. Para concluir esta atividade o entrevistado demorou cerca de 4 minutos e executou uma série de 30 passos, não sendo identificados problemas técnicos durante a execução.

Em relação a atividade A2 convém ressaltar que a opção de privacidade no envio de mensagens não é exibida quando o acesso é realizado pelo link m.facebook.com seja usando o navegador Firefox ou Internet Explorer.

Para realizar a atividade A3 foi necessário auxiliar o entrevistado na localização da opção, pois a navegação pelos links disponíveis usando a tecla "K", diferentemente da tecla $\mathrm{TAB}$, não desloca o cursor na tela fazendo com que o entrevistado selecione uma opção e o navegador execute uma ação diferente. Após ter sido identificado a divergência de comportamento na navegação entre os links, o entrevistado conseguiu executar a tarefa. Computando-se todo o tempo chegou-se a um total de 70 passos executados e tendo decorrido 10 minutos.

$\mathrm{Na}$ etapa final, onde o entrevistado poderia deixar quaisquer comentários que desejasse 
sobre a pesquisa e sobre a interação com o Facebook, o entrevistado comentou que gosta muito de usar o computador e explorar o Facebook apesar das dificuldades encontradas em seu cotidiano.

Esta entrevista demonstrou que, apesar da experiência e destreza que o entrevistado possui no uso do computador, a acessibilidade das funções de privacidade do Facebook é um item que precisa ser aprimorado. Mesmo acessando pelo link m.facebook.com as dificuldades foram visíveis e as tarefas exigiram também muitos passos para serem executadas.

\subsection{Entrevista 3}

O entrevistado número 3 utiliza o computador a bastante tempo, no entanto sua conta no Facebook é recente. É uma pessoa muito ativa na sociedade e no grupo, foi um dos fundadores da AJIDEVI, intermediou a criação do laboratório de informática da associação através de parceria com o projeto Acesso Digital e é agora candidato a vereador. $\mathrm{Na}$ primeira etapa da avaliação tudo transcorreu bem, sendo que as 11 perguntas efetuadas foram respondidas sem problemas. Na segunda etapa, não houve possibilidade da realização da mesma, pois o entrevistado utiliza o Facebook sempre com uma terceira pessoa para fazer a intermediação. Questionado sobre o porquê desta situação, esclareceu que o seu interesse no Facebook foi devido a ser a rede social mais utilizada no mundo hoje e devido estar passando por um momento de transição profissional achou ser interessante fazer parte da rede social para marketing profissional e político. Acha a interação muito complicada e por isso utiliza sempre com a intermediação dessa terceira pessoa. Possui conta no Twitter a uns três anos aproximadamente e interage sozinho no Twitter, pois o Twitter possui aplicativos gratuitos que o tornam mais acessível para os deficientes visuais. Como o Twitter já havia sido mencionado na preferência do participante do teste piloto, decidiu-se manter este entrevistado na pesquisa e investigar um pouco mais esta questão. $\mathrm{O}$ entrevistado sugere o desenvolvimento de aplicativos que tornem o Facebook mais acessível, como foi feito para o Twitter, tanto para a aplicação desktop como para a aplicação móvel. Investigando um pouco mais esses aplicativos, descobriu-se que existem pelo menos dois aplicativos para desktop (Qwitter e The Qube) e um para celular (Twitter 60 Pro), que tornam o Twitter mais acessível para os deficientes visuais. Além disso, o Twitter possui um aplicativo facilitador da publicação de fotos, vídeos, entre outros, o que facilita em muito a vida dos deficientes visuais.

Segundo o entrevistado, se houvesse essa acessibilidade no Facebook, não haveria a necessidade da intermediação de uma terceira pessoa e muito mais deficientes visuais usariam o Facebook.

$\mathrm{Na}$ etapa final, onde o entrevistado poderia deixar quaisquer comentários que desejasse sobre a pesquisa e sobre a interação com o Facebook, foi comentado sobre a importância do tema da pesquisa e sugerido novamente o desenvolvimento de aplicativos gratuitos que 
tornem o Facebook mais acessível.

Nesta entrevista ficou ainda mais clara a dificuldade de navegação do Facebook. Mesmo sendo este usuário um usuário mais experiente, por ser uma pessoa bastante ocupada não dispõe de tempo para navegar com tanta dificuldade, por isso opta pela intermediação de uma terceira pessoa para manter-se na rede social.

\subsection{Entrevista 4}

O entrevistado número 4 possui um perfil de intermediário para avançado. É uma pessoa bastante ativa, trabalha e faz faculdade. A avaliação foi feita na versão para desktop, no site facebook.com.br, utilizando sistema operacional Windows 7, navegador Internet Explorer versão 8.0 e Jaws versão 13.0. Na primeira etapa da avaliação tudo transcorreu bem, sendo que as 11 perguntas efetuadas foram respondidas sem problemas. Na segunda etapa, a atividade A1 foi realizada na sua totalidade em aproximadamente 5 minutos e com um total de aproximadamente 10 passos, sendo que não foram registrados problemas técnicos na execução desta atividade. O entrevistado demonstrou saber onde configurar e executou a tarefa sem nenhuma intervenção do entrevistador.

$\mathrm{A}$ atividade A2 não foi concluída devido o Facebook não abrir o botão necessário através do teclado quando utilizado o leitor de tela, mesmo caso do teste piloto, porém nesta interação o sistema aparentemente travou (para o observador), mas o leitor de tela voltou ao início da página e começou a leitura da página novamente. Como esta situação já havia sido observada na Entrevista 1, não foi feita nova tentativa para a realização da mesma, sendo a atividade abandonada.

A atividade A3 foi realizada na sua totalidade em aproximadamente 10 minutos e com um total de aproximadamente 20 passos, sendo que não foram registrados problemas técnicos na execução desta atividade. $\mathrm{O}$ entrevistado demonstrou não saber ao certo onde configurar, o que exigiu certo direcionamento do entrevistador, e demorou um pouco pois precisou voltar alguns passos para encontrar o link desejado.

$\mathrm{Na}$ etapa final, onde o entrevistado poderia deixar quaisquer comentários que desejasse sobre a pesquisa e sobre a interação com o Facebook, foi comentado sobre a dificuldade da interação, mencionando que apesar de utilizar, o Facebook ainda apresenta muitos problemas de acessibilidade como o ocorrido, onde trava o sistema ou volta ao começo da página.

Nesta entrevista, o próprio entrevistado ratifica a percepção da equipe de que apesar de alguns deficientes visuais utilizarem o Facebook, a dificuldade de interação e os problemas de acessibilidade são muitos.

\subsection{Entrevista 5}

$\mathrm{O}$ entrevistado número 5 possui um perfil de intermediário para avançado. É uma pessoa bastante ativa, trabalha e é esportista, participando ativamente de várias competições pelo Brasil. A avaliação foi feita na versão para desktop, no site facebook.com.br, 
utilizando sistema operacional Windows 7, navegador Internet Explorer versão 8.0 e Jaws versão 13.0. Na primeira etapa da avaliação tudo transcorreu bem, sendo que as 11 perguntas efetuadas foram respondidas sem problemas. Na segunda etapa, a atividade A1 foi realizada parcialmente em aproximadamente 15 minutos e com um total de aproximadamente 25 passos. Considerada realização parcial pois precisou da intervenção do entrevistador, passando várias vezes pelo link sem conseguir acessar corretamente (botão para abrir o submenu). Depois de voltar várias vezes, conseguiu finalizar.

$\mathrm{A}$ atividade $\mathrm{A} 2$ não foi concluída devido o Facebook não abrir o botão necessário através do teclado quando utilizado o leitor de tela, mesmo caso do teste piloto, porém nesta interação o sistema aparentemente travou (para o observador), mas o leitor de tela voltou ao início da página e começou a leitura da página novamente. Como esta situação já havia sido observada nas entrevistas anteriores, a atividade foi abandonada.

A atividade A3 foi realizada na sua totalidade em aproximadamente 10 minutos e com um total de aproximadamente 15 passos, sendo que não foram registrados problemas técnicos na execução desta atividade. $\mathrm{O}$ entrevistado demonstrou não saber ao certo onde configurar, o que exigiu certo direcionamento do entrevistador, mas concluiu a atividade sem problemas. Este participante costuma interagir no Facebook, no entanto observou-se nas suas interações que muitas postagens são feitas via Twitter, pois possui um aplicativo no
Facebook que ao postar no Twitter o aplicativo replica a postagem no Facebook.

$\mathrm{Na}$ etapa final, onde o entrevistado poderia deixar quaisquer comentários que desejasse sobre a pesquisa e sobre a interação com o Facebook, comentou sobre a questão dos aplicativos que tornam o Twitter mais acessível, sugerindo também que o Facebook poderia melhorar a interação para os deficientes visuais através de aplicativos desenvolvidos para esta finalidade. Também mencionou que gostou de participar da pesquisa e acha importante a iniciativa de melhoria.

Nesta entrevista, mais uma vez foi mencionado o Twitter com seus aplicativos que facilitam a interação, reforçando a dificuldade da navegação do Facebook.

\section{Conclusões}

Este trabalho realizou a avaliação das funções de privacidade do Facebook, buscando refletir sobre a área de IHC pode contribuir para a qualidade das interações humanas mediadas por tecnologias computacionais e avaliar as interfaces que permitem essas interações, papel que cabe aos profissionais de IHC. Observouse o quanto realmente é importante a avaliação dessas interfaces, principalmente a acessibilidade, proposta neste trabalho, pois as interações humanas através das redes sociais é um processo crescente e irreversível. Diante do exposto neste trabalho, observou-se que, apesar das dificuldades de acessibilidade, os deficientes visuais se empenham em utilizar o 
Facebook, pois querem sentir-se incluídos nos ambientes e atividades cotidianas, e usufruir dos seus direitos de igualdade de acesso. Percebeu-se que ainda não se pensa muito em acessibilidade, sendo este um tópico que precisa ser trabalhado fortemente pelos profissionais de IHC em aplicações de redes sociais como o Facebook. Além das visíveis dificuldades com o Facebook, foco da avaliação, os entrevistados mencionaram as dificuldades que encontram em sites como os das companhias aéreas, por exemplo, que segundo eles não são nada acessíveis.

A dificuldade de acesso que mais chama a atenção nesta avaliação é a quantidade de passos que são necessários para que os deficientes visuais consigam realizar as atividades, por exemplo, o ocorrido com o entrevistado 2 na atividade A3, que foi preciso em torno de 70 passos para realizar a atividade. Mesmo a atividade que foi realizada em menos passos, foram necessários 10 passos para a realização da mesma (Entrevistado 4 na atividade $\mathrm{A} 1)$.

Além disso, há os casos em que não funciona o acesso via teclado, caso da atividade A2 que não pode ser realizada e da senha no m.facebook.com, que exigiu a intervenção do entrevistador via mouse.

Acredita-se que a avaliação com este públicoalvo tendo a participação efetiva dos usuários, revelou de forma clara estes problemas de acessibilidade dos recursos de privacidade do Facebook. Além disso, a opinião dos usuários em relação a qualidade de uso do sistema, coletada nas entrevistas, mostra que as interações são dificultosas e precisa melhorar.

Diante destes resultados, fica clara a importância do trabalho realizado e espera-se contribuir para a melhoria da acessibilidade no Facebook, através da divulgação deste trabalho.

\section{Referências}

ALADI, 2003. La Brecha Digital y sus Repercusiones en los Países Miembros de la ALADI [The Digital Divide and Its Impact on ALADI Member Countries], Asociación Latinoamaricana de Integración [Latin American ASsociation for Integration] ALADI, 194 pp.

BRASIL. Decreto Legislativo N. 186, de 09 de Julho de 2008. Lex: DOU 10.07.2008, republic. Em 20.08.2008. Senado Federal, Brasília, 3 trim. 2008.

BRASÍLIA. Ministério do Planejamento, Orçamento e Gestão - Secretaria de Logística e Tecnologia da Informação Departamento de Governo Eletrônico em Cooperação com Ministério da Educação Secretaria de Educação Profissional e Tecnológica - Rede Nacional de Pesquisa e Inovação - Projeto de Acessibilidade Virtual. (2009). e-MAG Leitores de Tela, descrição e comparativo. Brasília, Brasil: Author.

KIMURA, M. H.; MANTAU, M. J.; KEMCZINSKI, A; GASPARINI, I.; BERKENBROCK, C. D. M. Usability evaluation of Facebook's privacy features: comparison of experts and users. IADIS International Conference WWW/INTERNET (ICWI), 2012, p. 290297.

DIAS, CLAUDIA. Usabilidade na Web: Criando Portais mais Acessíveis. 2ed. Rio de Janeiro: AltaBooks, 2007.

GIL, M. Deficiência Visual. MEC, Secretaria de Educação à distância, Brasília, 2000.

IBGE - Sala de Imprensa, Censo Demográfico, 


\section{ReLAlnEP}

Resultados Preliminares da Amostra.

Disponível em http://www.ibge.gov.br/home/presidencia/not icias/noticia_visualiza.php?id_noticia $=2018$ \& id_pagina $=1$.

Nonvisual Desktop Access - NVDA. Disponível em http://www.nvda-project.org/. Acesso em 29/06/2012.

PASCOLINI D. E MARIOTTI S.P.M. Global estimates of visual impairment: 2010. British Journal Ophthalmology Online First published December 1, 2011 as 10.1136/bjophthalmol-2011-300539.

Princípios do Facebook. Disponível em https://www.facebook.com/principles.php.

WORLD HEALTH ORGANIZATION. World report on disability. Geneva, World Health Organization, 2010.

WORLD WIDE WEB CONSORTIUM (W3C). Web Accessibility Initiative (WAI). $2012 . \quad$ Disponível em http://www.w3.org/WAI/intro/accessibility.p hp. 